\title{
Spectrum of neurological disorders admitted in Tribhuvan University Teaching Hospital Maharajgunj
}

\author{
Gajurel B P, Parajuli P, Nepali R, Oli K K \\ Department Of Neurology and Internal Medicine, Tribhuvan University Teaching Hospital, Maharajgunj
}

Correspondence address: Dr. Bikram Prasad Gajurel, Department Of Neurology, Tribhuvan University Teaching Hospital, Maharajgunj

Email: bikram_gajurel@yahoo.com

\begin{abstract}
Introduction: Neurologic disorders are very common. Data on the type and burden of neurological cases either in the outpatient and inpatient settings in our country are not available. This research has been done to perform a descriptive analysis of the spectrum of neurological cases which were admitted over a period of one fiscal year in Tribhuvan University Teaching Hospital (TUTH), Maharajgunj, Kathmandu

Methods: This retrospective study included all patients who were admitted with any neurological complaints over a period of one fiscal year (Shrawan 2067 B.S. to Asar 2068 B.S).

Results: The total number of patients admitted was 1165. Out of these, 693 cases were due to neurological disorders (59.48\%). The most common disorders were stroke, seizure disorder and central nervous system infections.
\end{abstract}

Conclusion: A variety of neurological disorders, from very common to very rare, were admitted.

Key Words: Neurologic disorders

\section{Introduction}

The brain, spinal cord and peripheral nerves constitute a system which perceives the environment, a person's behavior within it, and the maintenance of the body's internal milieu in readiness for this behavior. Disorders of the nervous system are very common and costly. ${ }^{1}$ Most patients with neurologic symptoms seek care from internists and other generalists rather than from neurologists. A large proportion of patients visit the outpatient clinics with minor to major neurological complaints. A major proportion of inpatient admissions in general medical hospital comprises of patients with various types of neurological disorders.

According to recent estimates by the World Health Organization, neurologic disorders affect over one billion people worldwide, constitute $6.3 \%$ of the global burden of disease, and cause $12 \%$ of global deaths. ${ }^{2}$ Neurological disorders contribute to $10.9 \%, 6.7 \%, 8.7 \%$ and $4.5 \%$ of the global burden of disease in high, upper middle, lower middle and low income countries, respectively. 2 The higher burden in the lower middle category reflects the double burden of communicable diseases and non-communicable diseases. Some $10 \%$ of the population in the United
Kingdom consult their general practitioner each year with a neurological symptom, and neurological disorders account for about one-fifth of acute medical admissions and a large proportion of chronic physical disability in the United Kingdom. ${ }^{3}$ The major neurological disorders encountered by neurologists in the United Kingdom were comprised by cerebrovascular diseases, seizure disorders, peripheral neuropathies, neurodegenerative diseases, multiple sclerosis and myelopathy., Epilepsy (27.0\%), headache $(19.0 \%)$ and cerebrovascular disorders $(7.8 \%)$ were the commonest problems encountered by neurologists in India.6 Data on the type and burden of neurological cases either in the outpatient and inpatient settings in our country are not available.

\section{Methods}

This is a retrospective study. Ethical clearance was obtained from the Institutional Review Board of the Research Department. All patients who were admitted with any neurological complaints were included in the study. The data of patients admitted over a period of one fiscal year (Shrawan 2067 B.S. to Asar 2068 B.S) were obtained from hospital records. The data were entered in computerized 
statistical analysis tool and were descriptively analyzed. Disorders like subarachnoid hemorrhage, brain and spinal tumors, traumatic brain and spinal cord injuries, compressive myelopathies and obstructive hydrocephalous are managed by the neurosurgical team in our hospital and are not included in this study.

\section{Results}

The total number of patients admitted in the medicalwards, including intensive care units, in TUTH from Shrawan 2067 B.S. to Asar 2068 B.S. was 1165. Out of these cases, 693 cases were due to neurological disorders (59.48\%) (Fig. 1).

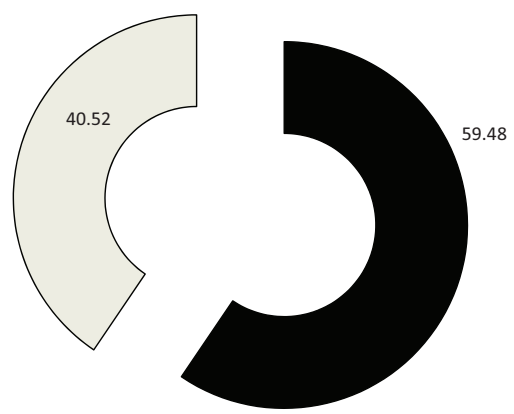

Neurological Cases 口Other Diseases

Fig. 1: Depicting the proportion of neurological cases admitted in one year.

The total number of cases admitted in each of the twelve months is as outlined in the figure below (Fig. 2).

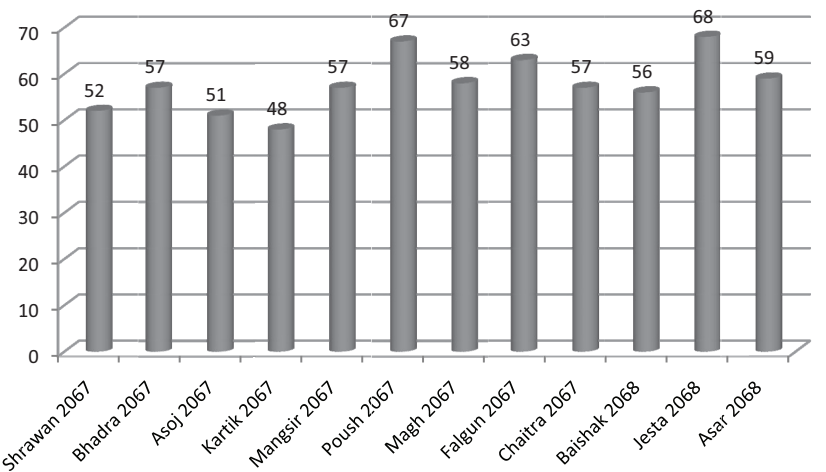

Fig. 2: Month-wise distribution of neurological disorders

The total number of male patients was $384(55.4 \%)$ and the total number of female patients was 309 (44.6\%) (Fig. 3).
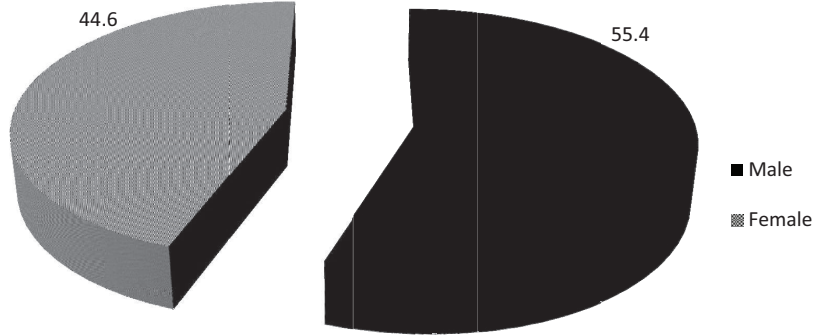

Fig. 3: Sex distribution of the patients

The age range of the patients was very wide, from as low as 15 years to as high as 100 years. The mean age of the patients was 51.93 with the standard deviation of 20.92 .

The spectrum of cases admitted in a period of one year is presented in the table (Table 1) below.

Table 1: Disease frequency over a one year period.

$\begin{array}{lll}\text { Type of Disease } & \text { Frequency } & \text { Percent } \\ \text { Ischemic Stroke } & 253 & 36.5 \\ \text { Hemorrhagic Stroke } & 90 & 13.0 \\ \text { Encephalitis } & 69 & 10.0 \\ \text { Seizure Disorder } & 68 & 9.8 \\ \text { Tubercular Meningitis } & 44 & 6.3 \\ \text { Bacterial Meningitis } & 35 & 5.1 \\ \text { Transverse Myelitis } & 29 & 4.2 \\ \text { Inflammatory Neuropathy } & 24 & 3.5 \\ \text { Parkinsons Disease } & 14 & 2.0 \\ \text { Motor Neurone Disease } & 10 & 1.4 \\ \text { Myasthenia Gravis } & 7 & 1.0 \\ \text { Dementia } & 7 & 1.0 \\ \text { Suspected Multiple Sclerosis } & 6 & .9 \\ \text { Sinus Thrombosis } & 6 & .9 \\ \text { Others } & 31 & 4.5 \\ \text { TOTAL } & \mathbf{6 9 3} & \mathbf{1 0 0 . 0}\end{array}$

Ten cases of tuberculous meningitis were associated with concomitant HIV infection. Thirteen of the 68 (19.1\%) cases of seizure disorders were due to neurocysticercosis. Of the inflammatory neuropathies, $19(79.2 \%)$ were cases of Guillain-Barre syndrome and five were due to chronic inflammatory demyelinating neuropathy.The category included as others comprised a variety of cases. There were four cases of benign intracranial hypertension. Transient ischemic attacks, tuberculomas, headaches, and cauda-equina syndrome comprised three cases each. There 
were two cases of each of toxoplasmosis, normal pressure hydrocephalous, optic neuritis and multiple cranial nerve palsies. Both the cases of toxoplasmosis were associated with HIV infection. Single cases of viral meningitis, Duchenne muscular dystrophy, generalized dystonia, leprous neuritis, hypokalemic periodic paralysis, neurosyphilis and progressive myoclonic encephalopathy.

Of the 693 cases, $594(85.7 \%)$ patients improved, 66 (9.5\%) died, 10 (1.4\%) patients were discharged on persistent request (DOR) and 23 (3.3\%) left the hospital against medical advice (LAMA) (Fig. 4).

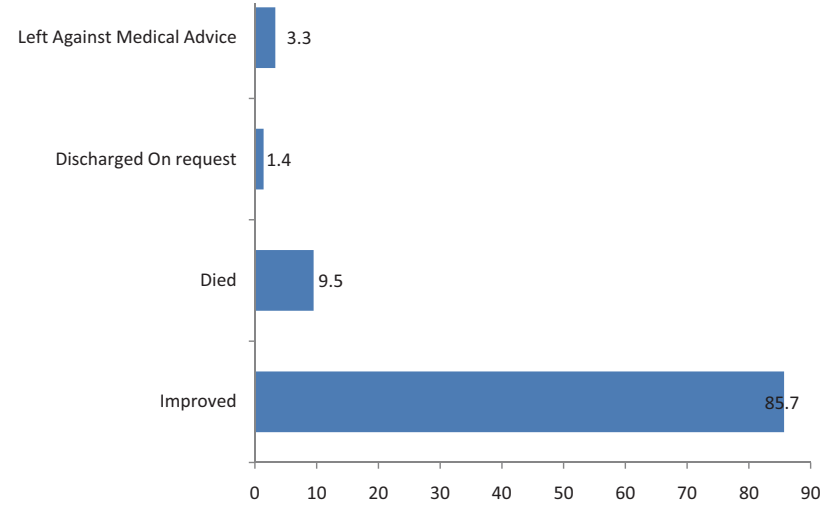

Fig. 4: The outcome of patients admitted.

Disease-wise outcomes are given in the following table (Table 2).

Table 2: Outcome of different disorders.

\begin{tabular}{|c|c|c|c|c|c|}
\hline \multirow[t]{2}{*}{ Disease } & \multicolumn{4}{|l|}{ Outcome } & \multirow[t]{2}{*}{ Total } \\
\hline & Improved & Dead & DOR & LAMA & \\
\hline Ischemic Stroke & 225 & 21 & 2 & 5 & 253 \\
\hline Hemorrhagic Stroke & 67 & 13 & 4 & 6 & 90 \\
\hline Encephalitis & 52 & 15 & 0 & 1 & 69 \\
\hline Seizure Disorder & 60 & 4 & 3 & 1 & 68 \\
\hline Tubercular Meningitis & 37 & 3 & 1 & 3 & 44 \\
\hline Bacterial Meningitis & 32 & 1 & 0 & 2 & 35 \\
\hline Transverse Myelitis & 27 & 2 & 0 & 0 & 29 \\
\hline Inflammatory Neuropathy & 23 & 0 & 0 & 1 & 24 \\
\hline Parkinson's Disease & 13 & 1 & 0 & 0 & 14 \\
\hline MND & 8 & 2 & 0 & 0 & 10 \\
\hline Myasthenia Gravis & 5 & 0 & 0 & 2 & 7 \\
\hline Dementia & 7 & 0 & 0 & 0 & 7 \\
\hline Suspected Multiple Sclerosis & 6 & 0 & 0 & 0 & 6 \\
\hline Sinus Thrombosis & 5 & 1 & 0 & 0 & 6 \\
\hline Others & 27 & 3 & 0 & 1 & 31 \\
\hline Total & 594 & 66 & 10 & 23 & 693 \\
\hline
\end{tabular}

MND: Motor Neurone Disease; DOR: Discharged On Request; LAMA: Left Against Medical Advice 


\section{Discussion}

Tribhuvan University Teaching Hospital, Maharajgunj is a tertiary care hospital and a referral central hospital in Nepal. Patients from all over Nepal come here for expert care and advice. More than half of admitted cases are constituted by neurological disorders (Fig. 1). The number of cases that are admitted in neurology side show the true scenario of hardships experienced by the service providers in the field. The admission rates have been uniform throughout the whole year (Fig. 2). Almost equal proportions of male and female patients have been admitted(Fig. 3) and a wide range of patients from age as low as 15 years to as high as 100 years have been admitted. This shows the range of services offered in the field.

The most common neurological disorders admitted in our setup are cerebrovascular diseases, seizure disorders, inflammatory and infective diseases (Table 1). This finding is consistent with the data that have been published in international articles. ${ }^{2,4-6}$ After stroke, the major burden of neurological diseases is constituted by various types of central nervous system infections. After encephalitis, tuberculous meningitis leads infectious disease. This is easy to understand as tuberculosis is a very common infectious disease in developing country like ours. HIV infection also seems to be a common disease and like in other countries it has been seen to be associated almost exclusively with tuberculosis, i.e. tubercular meningitis.

The spectrum of cases admitted is vivid evidence that almost all types of cases get admitted. The case may be as common as a stroke to as rare as generalized dystonia and progressive myoclonic encephalopathy. However, when the cases are analyzed on monthly basis, there seems no seasonal preponderance of any of the admitted cases. Almost all cases have been admitted uniformly throughout the year, except for rare cases.

The death rate of patients admitted with neurological cases $(9.5 \%)$ matches the data published in international articles. ${ }^{2}$ The death rate might be even more higher as we do not know what happened to the patients who were discharged on request and those who had left the hospital against medical advice (Fig. 4). Some family members take their patients away when the patient does not improve and is in the verge of death.

The maximum death rate is among patients with encephalitis, about $21.7 \%$ (Table 2). A large proportion of patients with tubercular and pyogenic infections have improved. This can be attributed to availability of effective antimicrobial agents against tubercular and pyogenic organisms and almost total lack of antiviral agents against common viral pathogens prevalent in Southeast Asia.
The death rate among hemorrhagic stroke patients is higher than that among ischemic stroke patients $(14.4 \%$ vs. $8.3 \%$ ) (Table 2). This scenario is also true elsewhere. There is very less death among patients with inflammatory neuropathy. It can be because of availability of appropriate intensive care in our hospital. Most cases of motor neurone disease, Parkinsons disease and dementia had improved because they were admitted usually for chest infections or dyselectrolytemia.

\section{Conclusion}

Till date, this is the only study of the type published in literature from Nepal. It can be seen that a large number of cases with a wide difference in ages get admitted in Tribhuvan University Teaching Hospital, Maharajgunj. This provides the opportunity to get acquaintances to a varietyof neurological cases in this hospital. This increases the confidence of trainee neurologists, trainee internists as well as medical students. It also provides the opportunity to carry out researches on various diseases in a single setting. Tribhuvan University Teaching Hospital is an ideal place to study and to carry out research.

\section{References}

1. Lowenstein DH, Martin JB, Hauser SL. Approach to the patient with neurologic disease. In: Longo DL, Kasper DL, Fauci AS, Hauser SL, Jameson JL, Loscalzo J editors. Harrison's principles of internal medicine. 18th ed. New York: McGrawHill, Medical Publishing Division; 2012. p. 3233.

2. World Health Organization. Neurological Disorders: Public Health Challenges. Geneva. WHO Press. 2006.p. 27-39.

3. Allen CMC, Lueck CJ, Davidson MD. Neurological diseases. In: Colledge NR, Walker BR, Ralston SH editors. Davidson's Principles and Practice of Medicine. 21st ed. Edinburgh: Elsevier, Churchill Livingstone; 2010. p. 1134.

4. Hopkins A, Menken M, DeFriese G. A record of patient encounters in neurological practice in the United Kingdom. Journal of Neurology, Neurosurgery, and Psychiatry 1989;52:436-438

5. Perkin GD. Necessity for inpatient services in neurological practice. Journal of the Royal Society of Medicine. Volume 76 November 1983

6. Singhal BS, Gursahani RD, Menken M. Practice patterns in neurology in India. Neuroepidemiology. 1992;11(3):158-62. 